International Journal of Pure and Applied Mathematics

Volume 97 No. 4 2014, 497-510

ISSN: 1311-8080 (printed version); ISSN: 1314-3395 (on-line version)

url: http://www.ijpam.eu

doi: http://dx.doi.org/10.12732/ijpam.v97i4.9

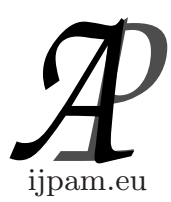

\title{
EFFICIENCY EVALUATION \\ OF THE ALUMINUM MARKET USING RANDOM WALK
}

\author{
C. Muñóz Ibáñez ${ }^{1}$, G. Pérez Lechuga ${ }^{2}$, F. Venegas Martínez ${ }^{3} \S$ \\ ${ }^{1}$ Universidad Autónoma del Estado de Hidalgo \\ ICBI, MÉXICO \\ ${ }^{2}$ Universidad Autónoma del Estado de Hidalgo \\ Escuela Superior de Apan, MÉXICO \\ ${ }^{3}$ Instituto Politécnico Nacional \\ Escuela Superior de Economía, MÉXICO
}

\begin{abstract}
An efficient market is one where prices of traded securities reflect all available information and adjust fully and quickly to new information. When one market is efficient changes in stock prices are unpredictable and therefore behave as a random walk.

Our aim to test the efficiency of the international metals market by analyzing their behavior in the London Metal Exchange or LME for its acronym in English, and PLATTS developed by Mc Graw Hill Company. Both indicators are the primary benchmark to determine the base price for metal parts (aluminum) in the automotive industry.

To do this, we take a monthly publication from January 2009 until August 2013, of the metal prices reported in PLATTS and LME. Various statistical tests were applied to determine the stationarity of the sample generated, such as the Autocorrelation Function, the Ljung-Box Test, the Unit Root Test, the Dickey-Fuller Test and the Augmented Dickey-Fuller Test. We concluded that the analyzed series are non-stationary for the case studied, showing a strong statistical evidence that, the international market of the aluminum is efficient and follows a random walk.
\end{abstract}

Received: July 6, 2014

(C) 2014 Academic Publications, Ltd.

${ }^{\S}$ Correspondence author url: www.acadpubl.eu 
AMS Subject Classification: 90A, 90B

Key Words: efficient markets, random walk, stationary series, statistics test, autocorrelation function

\section{Introduction}

The establishment of market efficiency in the metal-mechanical industry is important because, based on this assumption, we can determine the changes in the price of metals, which could come given as a random walk and so therefore, the pricing of the securities could be adjust to the available information [1].

Therefore, it is significant to establish the hypothesis that efficient markets have important implications in determining the prices of metals, such as in the context of financial markets, the decisions of individual investors and in the field of management company [2]. If markets are efficient, prices reflect all available information about the intrinsic value or fundamental of each security, protecting the small investor the damage which might arise from their lack of experience or knowledge about the functioning of the market [3]. Thus, an efficient market is a fair market where all investors, specialized or not, have the same degree of information and therefore the same chance of winning or losing.

In an efficient market, the price of assets (in this case metal prices) fluctuate randomly about its intrinsic value [2], therefore the development of asset pricing models, together with the review of the efficiency of markets, constitutes the pillars on which the studies of capital markets settle. Our work focuses on determining the efficiency of the aluminum market and for this, we rely on the methodology and analysis given by [4]. Therefore, in the remainder of this document we approach our work based on the ideas of these authors.

The prediction on the price change has always been a topic of great importance in the study of finance. However, surprisingly, few things had been published until Kendall [6]. This author conducted studies that found that the weekly price changes in a variety of financial series can not be predicted either by past changes in the series or in other series of past price changes [4]. This may have been the first explicit report of the properties of financial prices, the study would lead subsequent to the property called "market efficiency". However, subsequent work by Roberts [7] and Osborne [8], presented a comprehensive analysis that developed the proposition that there are prices in absolute value but the logarithmic price changes which are independent, which is based on the assumption that these auxiliary changes normally distributed [9].

The random walk theory states that market and securities prices are random 
and not influenced by past events. The idea is also referred to as the "weak form efficient-market hypothesis." The central idea behind the random walk theory is that the randomness of stock prices renders attempts to find price patterns or take advantage of new information futile. In particular, the theory claims that day-to-day stock prices are independent of each other, meaning that momentum does not generally exist and calculations of past earnings growth does not predict future growth [32].

Historically, there was a very close link between the efficient-market hypothesis, the random walk hypothesis and then the Martingale model. The random character of stock market prices was first modelled by Jules Regnault, a French broker, in 1863 and then by Louis Bachelier [10], a French mathematician, in his $1900 \mathrm{PhD}$ thesis, "The Theory of Speculation". His work was largely ignored until the 1950s; however, beginning in the 1930s scattered, independent work corroborated his thesis. In fact, the basis for the current analysis of price series financial and its features were originally established by Bachelier; while, initially most readers did not understand the importance of the conclusions to which he came, his analysis has foundations that are valid even today.

Studies of market efficiency through the random walk hypothesis have been documented throughout the world. In Latin America, was made using various approaches, among which include: 1) Evidence of Serial Correlation Coefficient and Parametric in Runs Test, described by Sidney [31], 2) The Unit Root Tests of Dickey-Fuller [25], Phillips-Perron [27] and Kwiatkowski-Phillips [30], used to test the non-stationarity as a necessary condition for a random walk; 3) The Statistics of the Variance Ratio proposed by Lo and MacKinlay [29], used to test the random walk for various known distributions, and the Test of Multiple Variance Ratio developed by Chow and Denning [11], 4) The Test of Bartlett $[28], 5)$ The Q Statistic of Box and Pierce [12] and the Statistic of LB Ljung and Box [24], (information mentioned in [4]).

In Europe, studies have been conducted using random walk in Slovenia [13], Spain [14], Czech Republic [15], in the UK [16], in European equity markets, including countries such as Austria, Belgium, Denmark, Finland, France, Germany, Greece, Ireland, Italy, Netherlands, Norway, Portugal, Spain, Sweden, Switzerland and the United Kingdom and four emerging markets as Czech Republic, Hungary, Poland and Russia [17] and efficiency in European equity markets by María Rosa Borges [18], (information mentioned in [4]).

In the United States, was primarily Osborne who analyzed the stock prices. This author presented their results to other physicists and showed that the prices of the common shares are similar to the motion of the molecules prop- 
erties. He shown that common-stock prices, and the value of money can be regarded as an ensemble of decisions in statistical equilibrium, with properties quite analogous to an ensemble of particles in statistical mechanics $[4,8]$.

Subsequently, Moore [19] analyzed the first differences of the logarithms of the prices of eight shares of NYSE (New York Stock Exchange), leaning on the hypothesis that the distribution of returns is approaching a normal type, the prices seemed to move randomly and there was a predictable pattern of behavior, (information mentioned in [4]).

Fame [1], corroborates this view as to the daily returns of each of the thirty stocks that make up the Dow Jones Industrial Average. Another interesting study of market efficiency was conducted by Malkiel [32] after examining the attacks on the twin towers, and, again shows that professional investment managers do not exceed the index of points of reference. Also, this author provides evidence that prices in major markets seem to reflect all available information $[4]$.

Although scattered, there are some studies documented to establish the efficiency of the metals markets made by Sephton and Cochrane [20,4]. These authors performed a test of cointegration to establish market efficiency copper, zinc, aluminum and nickel finding that these markets are efficient. Subsequently, Kenourgios and Samitas [21] analyzed the hypothesis of market efficiency in the prices of metals reported by the LME. They found that the market is not efficient. On the other hand, Gwanak-ro Gwanak-gu and [22] realized studies in Korea in 2010 through of a cointegration model, for the period 1985-2008. They studied the markets for aluminum, zinc and copper and concluded that only the copper market was efficient, while aluminum and zinc were inefficient, (information mentioned in [4]).

In this document we use the random walk method to test the international efficiency of the aluminum market. Our hypotheses to test are given by: $H_{0}$ : the market of the aluminum prices reported by PLATTS and LME is efficient, and $H_{1}$ : the market of the aluminum prices reported by PLATTS and LME is not efficient.

\section{Methods and materials}

For the development of this research we obtained the aluminum prices reported by PLATTS and LME for the period from January-2009 to July-2013. These quantities correspond to the values of closing monthly rates during the men- 
tioned period. The interval is broad enough to determine whether the market is efficient or not, since it is considered both periods of stability and economic instability and political.

Data from the PLATTS and LME (Table (1)), for this study were subjected to statistical analysis using various tests for this goodness of fit in order to determine the stationarity of both.

Table (2) shows a summary of descriptive statistics of the price indexes of the aluminum reported in PLATTS and LME. These indices are negatives and asymmetrics indicating that there is a greater likelihood of large falls instead of increases in both cases. The Jarque-Bera statistic and the $p$-value are also showed. Since the index Jarque-Bera and the $p$-value are within the permitted level of significance (0.05), then we accept the null hypothesis that the values reported in PLATTS and LME for the aluminum price indices are normally distributed.

\begin{tabular}{||c|c|c|c|c|c||}
\hline Date & LME & PLATTS & Date & LME & PLATTS \\
\hline $01 / 01 / 2009$ & $2,165.00$ & $2,366.20$ & $01 / 04 / 2011$ & $1.292,00$ & $1.330,70$ \\
$01 / 01 / 2009$ & $2.165,00$ & $2.366,20$ & $01 / 05 / 2011$ & $1.190,00$ & $1.479,50$ \\
$01 / 02 / 2009$ & $2.190,00$ & $2.318,10$ & $01 / 06 / 2011$ & $1.420,00$ & $1.505,30$ \\
$01 / 03 / 2009$ & $2.230,00$ & $2.325,20$ & $01 / 07 / 2011$ & $1.650,00$ & $1.520,60$ \\
$01 / 04 / 2009$ & $2.190,00$ & $2.389,30$ & $01 / 08 / 2011$ & $1.705,00$ & $1.642,40$ \\
$01 / 05 / 2009$ & $2.170,00$ & $2.391,30$ & $01 / 09 / 2011$ & $1.680,00$ & $1.937,60$ \\
$01 / 06 / 2009$ & $2.170,00$ & $2.339,50$ & $01 / 10 / 2011$ & $1.700,00$ & $1.928,50$ \\
$01 / 07 / 2009$ & $2.130,00$ & $2.327,00$ & $01 / 12 / 2011$ & $1.950,00$ & $1.978,70$ \\
$01 / 08 / 2009$ & $2.121,00$ & $2.344,80$ & $01 / 01 / 2011$ & $1.930,00$ & $2.144,80$ \\
$01 / 09 / 2009$ & $2.160,00$ & $2.341,50$ & $01 / 02 / 2011$ & $1.937,00$ & $2.305,90$ \\
$01 / 10 / 2009$ & $2.192,00$ & $2.357,60$ & $01 / 03 / 2012$ & $2.060,00$ & $2.241,12$ \\
$01 / 11 / 2009$ & $2.285,00$ & $2.400,10$ & $01 / 04 / 2012$ & $2.210,00$ & $2.318,06$ \\
$01 / 12 / 2009$ & $2.280,00$ & $2.402,10$ & $01 / 05 / 2012$ & $1.870,00$ & $2.402,36$ \\
$01 / 01 / 2010$ & $2.380,00$ & $2.409,10$ & $01 / 06 / 2012$ & $1.865,00$ & $2.270,80$ \\
$01 / 02 / 2010$ & $2.740,00$ & $2.589,00$ & $01 / 07 / 2012$ & $1.850,00$ & $2.184,41$ \\
$01 / 03 / 2010$ & $2.680,00$ & $2.843,90$ & $01 / 08 / 2012$ & $2.145,00$ & $2.184,41$ \\
$01 / 04 / 2010$ & $2.690,00$ & $2.831,50$ & $01 / 09 / 2012$ & $2.200,00$ & $2.282,97$ \\
$01 / 05 / 2010$ & $2.660,00$ & $2.814,50$ & $01 / 10 / 2012$ & $2.186,00$ & $2.293,99$ \\
$01 / 06 / 2010$ & $2.590,00$ & $2.780,20$ & $01 / 11 / 2012$ & $2.200,00$ & $2.420,28$ \\
$01 / 07 / 2010$ & $2.530,00$ & $2.840,90$ & $01 / 12 / 2012$ & $2.230,00$ & $2.442,32$ \\
$01 / 08 / 2010$ & $2.440,00$ & $2.713,70$ & $01 / 01 / 2013$ & $2.290,00$ & $2.442,32$ \\
$01 / 09 / 2010$ & $2.140,00$ & $2.532,20$ & $01 / 02 / 2013$ & $2.336,00$ & $2.541,00$ \\
$01 / 10 / 2010$ & $1.420,00$ & $2.122,50$ & $01 / 03 / 2013$ & $2.375,00$ & $2.644,80$ \\
$01 / 11 / 2010$ & $1.270,00$ & $1.730,60$ & $01 / 04 / 2013$ & $2.759,00$ & $2.708,47$ \\
$01 / 12 / 2010$ & $1.045,00$ & $1.495,00$ & $01 / 05 / 2013$ & $2.630,00$ & $2.710,24$ \\
$01 / 01 / 2011$ & $1.025,00$ & $1.495,00$ & $01 / 06 / 2013$ & $2.508,00$ & $2.673,58$ \\
$01 / 02 / 2011$ & $1.103,00$ & $1.354,50$ & $01 / 07 / 2013$ & $2.589,00$ & $2.653,07$ \\
$01 / 03 / 2011$ & $1.206,00$ & $1.313,10$ & $01 / 08 / 2013$ & 0 & 0 \\
\hline
\end{tabular}

Table 1: Base price of a ton of aluminum in LME and PLATTS. 


\begin{tabular}{||c|c|c|c|c||}
\hline Index & Average & Maximum & Minimum & Standard d. \\
\hline LME & $2,050.34$ & $2,759.00$ & $1,025.00$ & 462.52 \\
PLATTS & $2,241.70$ & $2,843.90$ & $1,313.10$ & 425.07 \\
\hline Índice & Skewness & Kurtosis & Jarque-Bera & $p$-value \\
\hline LME & -0.6541 & 2.66 & 4.17 & 0.1240 \\
PLATTS & -0.7558 & 2.68 & 5.46 & 0.0651 \\
\hline
\end{tabular}

Table 2: Descriptive statistics of the stock indices of international aluminum prices

\subsection{The random walk hypothesis}

It is said that the random walk with drift "process" is characterized by the equation $Y_{t}=Y_{t-1}+\beta+\varepsilon_{t}$, or $r_{t}=\Delta Y_{t}=\beta+\varepsilon_{t}$, where $Y_{t}$ is the the price index reported in PLATTS an LME at time $t$. Here, $\beta$ is a parameter or abitrary drift, $r_{t}$ are the changes in the indices and $\varepsilon_{t}$ is a random error satisfying, $E\left(\varepsilon_{t}\right)=0, E\left(\varepsilon_{t}, \varepsilon_{t-g}\right)=0, g \neq 0$, for all $t$.

Under the random walk hypothesis, a market is efficient if the most recent price contains all available information, therefore, it is considered that this is the best predictor of prices. There are three versions of the random walk model, according to the classification suggested by Campbell, Lo and MacKinlay [23, 4]:

1. RW1: The first version requires that price increases are independent and identically distributed. Here, $Y_{t}=\mu+Y_{t-1}+\varepsilon_{t}$, where $\varepsilon_{t} \sim \operatorname{IID}\left(0, \sigma^{2}\right)$, $\mu$ is the expected value of the change in price, and $\sigma$ is the standard deviation. Since the increments are independent, the random walk is a far game but more demanding that the martingale, because independence implies that not only increases are not correlated but not linear functions of them are also not correlated.

Assume that prices follow a normal distribution implies that they can have negative prices. Then the natural logarithm of prices, represented by $P_{t}=\log Y_{t}$, follows a random walk with increments that follow a normal distribution, i.e, $P_{t}=\mu+P_{t-1}+\varepsilon_{t}$ with $\varepsilon_{t} \sim I I D N\left(0, \sigma^{2}\right)$, which leads to the Bachelier model [10].

2. RW2: This second version, requires only that increments be independent, without the need to submit the same distribution. Then, this version takes into account the heteroskedasticity in the increments, characteristic common in financial time series.

3. RW3: Finally, the random walk model only requires that the increases 
not be correlated, i.e, $\operatorname{Cov}\left(\varepsilon_{t}, \varepsilon_{t-k}\right)=0$, but admits that there dependence between them, i.e, $\operatorname{Cov}\left(\varepsilon_{t}, \varepsilon_{t-k}\right)=0$ for $k \neq 0$.

This provides a complementary number of tests of random walk and market efficiency

\subsection{Statistical analysis}

In this document, all the statistical analyzes were performed using the computational software EViews 8 for Windows.

The tests performed were: 1) the Sample Autocorrelation Function and the correlogram, 2) the Statistic of LB Ljung and Box [24], in order to test the statistical significance of the joint hypothesis that all autocorrelation coefficients are simultaneously equal to zero; and 3) the Dickey-Fuller Test involved in the process of making decisions [25] .

In analyzing the nature of the unit root process, it shows that a random walk process may have or not variations; or possibly have variations and deterministic trends. In order to enable the different possibilities, the Dickey-Fuller Test was estimated in three different ways [4]:

1. $Y_{t}$ is a random walk given by

$$
\Delta Y_{t}=\delta Y_{t-1}+u_{t} .
$$

2. $Y_{t}$ is a random walk with variations given by

$$
\Delta Y_{t}=\beta_{1}+\delta Y_{t-1}+u_{t} .
$$

3. $Y_{t}$ is a random walk with variations around a deterministic trend, i.e.,

$$
\Delta Y_{t}=\beta_{1}+\beta_{2} t+\delta Y_{t-1}+u_{t} .
$$

Where $t$ is the time or trend variable.

In each case the null hypothesis assumes that $\delta=0$; i.e, there is a unit root and the time series is not stationary. The alternative hypothesis assumes that $\delta<0$; that is, the time series is stationary. If the null hypothesis is rejected, this means that $Y_{t}$ is a stationary time series with zero mean. Notice that, for Equation (1) this means that $Y_{t}$ is stationary with zero mean. Similarly, for Equation (2), $Y_{t}$ is stationary with non-zero mean, and for Equation (3), $Y_{t}$ is stationary around a deterministic trend [4].

The estimation procedure for the Dickey-Fuller Test was as follows: 
1. The model is estimated by Equations (1), (2) or (3) by the method of ordinary least squares.

2. The estimated coefficient of $Y_{t-1}$ is divided in each case by its standard error to calculate the statistic $\tau$.

3. The Dickey-Fuller tables are queried.

If the calculated value of the statistic $\tau$ exceeds the allowable error of the Dickey-Fuller test, or the MacKinnon critical values [26], then, the null hypothesis is rejected (i.e., $\delta=0$ ), and the time series is stationary. Moreover, if $\tau$ calculated does not exceed the critical value, the time series is not stationary and the null hypothesis is accepted [4]. Using Equations (1), (2) and (3) and for $\alpha=0.05$, the critical values obtained with the experimental data, were -1.9439 , -2.8947 and -3.4614 ; respectively.

Decision-making is based on determining whether changes in aluminum prices represented by the LME PLATTS and internationally marking metals present a random behavior or not. If returns follow a "random walk" the null hypothesis is rejected and states that the international aluminum market is efficient.

\section{Results and Discussion}

When the time series are studied, it is useful to perform a graphical representation of the data in order to display if it can describe any kind of behavior that provides an initial clue to the possible nature of the time series. In Figure (1) we show a monthly graphical representation of the data from the PLATTS and LME during the period January 2009 to July 2013. Evaluation exhibits behavior that can be deemed as irregular or erratic, which intuitively, predicts a random behavior.

\subsection{Stationarity test based on the correlogram}

In this section we exhibit the stationarity test based on the autocorrelation function. This test is performed by calculating the lag between the first and subsequent observations. The exercise aims to evaluate the degree of auto correlation between recent evaluations and lagging evaluations of the indexes associated with aluminum prices, reported by LME and PLATTS. The autocorrelation function, $\rho_{k}$ of the lag $k$ is given by 


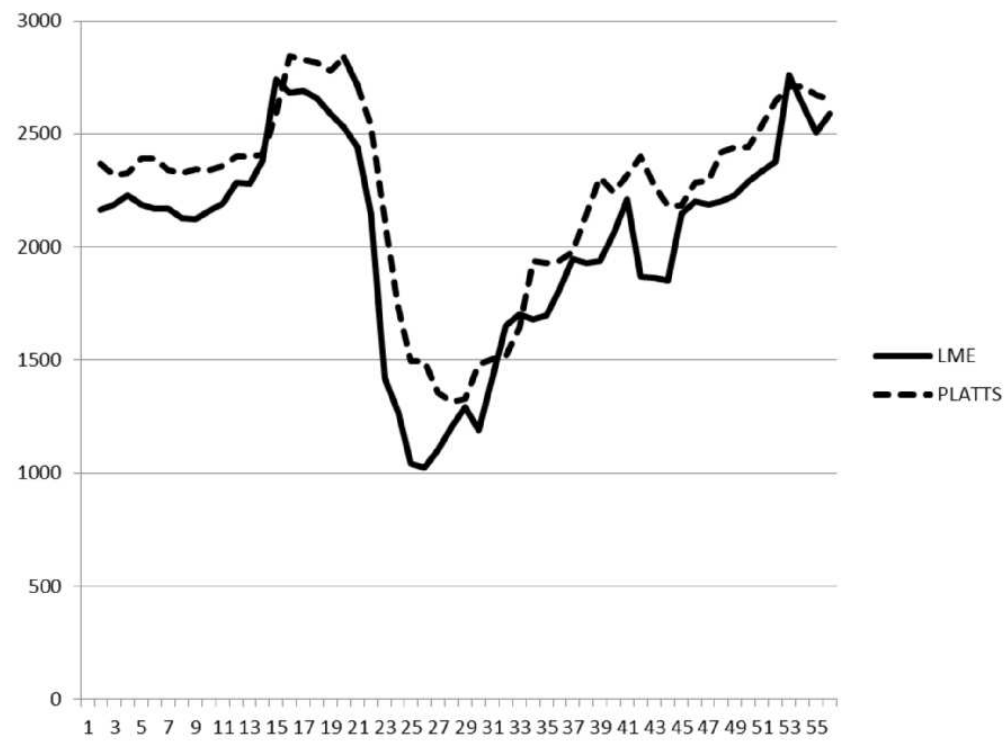

Figure 1: Behavior of the index values associated with aluminum prices

$$
\rho_{k}=\frac{\sum_{t=1}^{n-k}\left(Y_{t}-\bar{Y}\right)\left(Y_{t-k}-\bar{Y}\right)}{\sum_{t=1}^{n}\left(Y_{t}-\bar{Y}\right)^{2}},
$$

where $k$ is number of lags, $n$ is the sample size, $Y_{t}$ is the index number of the aluminum price reported by PLATTS or LME and $\bar{Y}$ is the sample mean of the serie. The corresponding correlograms and their parameters of the time series for PLATTS and LME for $n=24$ are shown in Figure (2). Notice that, the autocorrelation coefficient begins with a very high value for both $\left(\rho_{1}=\right.$ 0.948 for PLATTS and $\rho_{1}=0.923$ for LME) and declines very slowly as the lag continues.

Regarding the interpretation of the correlograms, Gujardi [5], suggests a practical rule for calculating FAC choosing lag length up to one third or half of the length of the time series. In this case, we have 55 observations, and according to the above rule, we shall choice between the lags 19 and 28. The observed results suggest that the series are non-stationary [4]. 


\begin{tabular}{|c|c|c|c|c|c|c|c|c|c|c|c|c|c|c|c|c|c|}
\hline \multicolumn{2}{|c|}{ Autocorrelation } & \multicolumn{2}{|c|}{ Partial Correlation } & \multirow{2}{*}{\multicolumn{2}{|c|}{$\begin{array}{c}A C \\
10.923\end{array}$}} & \multirow{2}{*}{$\frac{P A C}{0.923}$} & \multirow{2}{*}{$\frac{\text { Q-Stat }}{49.468}$} & \multirow{2}{*}{$\frac{\text { Prob }}{0.000}=$} & \multicolumn{2}{|c|}{ Autocorrelation } & \multicolumn{2}{|c|}{ Partial Correlation } & \multicolumn{2}{|r|}{$A C$} & \multirow{2}{*}{$\frac{\text { PAC }}{0.948}$} & \multirow{2}{*}{$\frac{\text { Q-Stat }}{52.134}$} & \multirow{2}{*}{$\begin{array}{c}\text { Prob } \\
0.000\end{array}$} \\
\hline 1 & 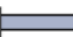 & 1 & & & & & & & 1 & & 1 & & 1 & 0.948 & & & \\
\hline 1 & & $\square$ & 1 & 2 & 0.812 & -0.273 & 88.444 & 0.000 & 1 & & $\square$ & 1 & 2 & 0.846 & -0.513 & 94.431 & 0.000 \\
\hline 1 & $\square$ & $1 \square$ & 1 & 3 & 0.677 & -0.183 & 116.06 & 0.000 & 1 & & 10 & 1 & 3 & 0.718 & -0.110 & 125.51 & 0.000 \\
\hline 1 & $\square$ & I므 & 1 & 4 & 0.524 & -0.165 & 132.91 & 0.000 & 1 & & 듬 & 1 & 4 & 0.571 & -0.171 & 145.58 & 0.000 \\
\hline 1 & $\square$ & 1 & 1 & 5 & 0.376 & -0.014 & 141.75 & 0.000 & 1 & $\square$ & 맘 & 1 & 5 & 0.405 & -0.232 & 155.86 & 0.000 \\
\hline 1 & $\square$ & 10 & 1 & 6 & 0.225 & -0.130 & 144.99 & 0.000 & 1 & 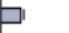 & 1 & 1 & 6 & 0.240 & 0.068 & 159.56 & 0.000 \\
\hline 1 & P & 1 & 1 & 7 & 0.091 & 0.008 & 145.53 & 0.000 & 1 & P & 1 & 1 & 7 & 0.093 & 0.038 & 160.12 & 0.000 \\
\hline 1 & 1 & 1 & 1 & 8 & -0.028 & -0.059 & 145.58 & 0.000 & 1 & 1 & 1 & 1 & 8 & -0.033 & -0.009 & 160.20 & 0.000 \\
\hline 10 & 1 & 1 & 1 & 9 & -0.121 & 0.032 & 146.58 & 0.000 & 1 & 1 & 1 & 1 & 9 & -0.138 & 0.002 & 161.49 & 0.000 \\
\hline 1므 & 1 & 1 & 1 & 10 & -0.186 & 0.014 & 148.99 & 0.000 & 1마 & 1 & 1 & 1 & 10 & -0.208 & 0.119 & 164.50 & 0.000 \\
\hline ㅁㅁㅁ & 1 & 1 & 1 & 11 & -0.224 & 0.033 & 152.56 & 0.000 & $\square$ & 1 & I며 & 1 & 11 & -0.254 & -0.162 & 169.11 & 0.000 \\
\hline$\square$ & 1 & 1 & 1 & 12 & -0.230 & 0.052 & 156.41 & 0.000 & ᄃ & 1 & 1 & 1 & 12 & -0.276 & 0.060 & 174.69 & 0.000 \\
\hline$\square$ & 1 & 10 & 1 & 13 & -0.230 & -0.110 & 160.36 & 0.000 & $\square$ & 1 & 19 & 1 & 13 & -0.288 & -0.168 & 180.86 & 0.000 \\
\hline$\square$ & 1 & 10 & 1 & 14 & -0.235 & -0.152 & 164.60 & 0.000 & $\square$ & 1 & 19 & 1 & 14 & -0.295 & -0.150 & 187.50 & 0.000 \\
\hline$\square$ & 1 & 1 & 1 & 15 & -0.234 & 0.001 & 168.87 & 0.000 & $\square$ & 1 & 10 & 1 & 15 & -0.307 & -0.133 & 194.89 & 0.000 \\
\hline 맘 & 1 & 10 & 1 & 16 & -0.236 & -0.070 & 173.37 & 0.000 & $\square$ & 1 & 1 & וב & 16 & -0.309 & 0.169 & 202.58 & 0.000 \\
\hline 맘 & 1 & 10 & 1 & 17 & -0.241 & -0.050 & 178.17 & 0.000 & $\square$ & 1 & 1 & 1 & 17 & -0.304 & -0.024 & 210.21 & 0.000 \\
\hline 무 & 1 & 10 & 1 & 18 & -0.255 & -0.094 & 183.67 & 0.000 & $\square$ & 1 & 10 & 1 & 18 & -0.302 & -0.082 & 217.92 & 0.000 \\
\hline$\square$ & 1 & 1 & 1 & 19 & -0.265 & 0.027 & 189.79 & 0.000 & $\square$ & 1 & 11 & 1 & 19 & -0.305 & -0.012 & 226.00 & 0.000 \\
\hline$\square$ & 1 & ㅁㅁㅁ & 1 & 20 & -0.291 & -0.179 & 197.40 & 0.000 & $\square$ & 1 & 1믹 & 1 & 20 & -0.309 & -0.168 & 234.53 & 0.000 \\
\hline$\square$ & 1 & 1 & 1 & 21 & -0.314 & 0.024 & 206.52 & 0.000 & $\square$ & 1 & 10 & 1 & 21 & -0.315 & -0.102 & 243.70 & 0.000 \\
\hline$\square$ & 1 & 10 & 1 & 22 & -0.334 & -0.071 & 217.15 & 0.000 & $\square$ & 1 & 18 & 1 & 22 & -0.323 & -0.030 & 253.59 & 0.000 \\
\hline$\square$ & 1 & 1 & 1 & 23 & -0.345 & 0.029 & 228.78 & 0.000 & $\square$ & 1 & & 1 & 23 & -0.332 & -0.109 & 264.36 & 0.000 \\
\hline$\square$ & 1 & 1 & 1 & 24 & -0.337 & -0.031 & 240.25 & 0.000 & $\square$ & 1 & 11 & וב & 24 & -0.324 & 0.139 & 274.99 & 0.000 \\
\hline
\end{tabular}

Correlogram for PLATTS

Correlogram for LME

Figure 2: Correlograms for PLATTS and LME

\subsection{The Ljung-Box Statistic}

Instead of testing the statistical significance of any individual autocorrelation coefficient, it can be proved the joint hypothesis that all the autocorrelation coefficients are simultaneously zero. For this, we used the Statistic of LB Ljung and Box [24] with $m$ degrees of freedom given by

$$
L B=n(n+2)=\sum_{k=1}^{m}\left(\frac{\rho_{k}^{2}}{n-k}\right) \sim \chi_{\alpha, m}^{2} .
$$

Here, $n$ is the sample size, $m$ the lag length, and $\rho_{k}$ is the sample autocorrelation coefficient. The criticality level of the test was $\alpha=0.5$.

When considering the data of PLATTS and LME, the values of this statistic until the lag 24 were 274.99 and 240.25 respectively. The probability of this happening is zero, under the null hypothesis that the sum of the 24 squares of the estimated autocorrelation coefficients are zero. Since the calculated LjungBox statistic values are greater than $\chi_{\alpha, m}^{2}=0.05,2436.4150$, the null hypothesis that simultaneously all $\rho_{k}=0$, is rejected. Therefore, the conclusions are that, 
both time series LME and PLATTS are non-stationary.

\subsection{The Unit Root Test}

An alternative method for assessing the stationarity of a series is to apply the Test of the Unit Root proposed by Dickey-Fuller [25]. We applied this test to the data of the time series PLATTS and LME. The results for the three models were (Equations (1), (2) and (3)):

1. $Y_{t}$ is a random walk. In other words, $\Delta_{t}=-0.001, \tau=-0.1576$ for PLATTS and $\Delta_{t}=-0.001, \tau=-0.0983$ for LME.

2. $Y_{t}$ is a random walk with variations, i.e., $\Delta_{t}=153.0928-0.0673, \tau=$ -2.0197 for PLATTS, and $\Delta_{t}=165.3206-0.0785, \tau=-1.6134$ for LME.

3. $Y_{t}$ is a random walk with variations around a deterministic trend, i.e., $\Delta_{t}=144.6858+0.2581 t-0.0668, \tau=-1.9816$ for PLATTS, and $\Delta_{t}=$ $133.8311+1.0012 t-0.0767, \tau=-1.5674$ para LME.

For the model of Equation (1), the estimated values of $\tau$ were -0.1576 and -0.0983 for PLATTS and LME respectively. These values must be lower than -1.9471 for $\alpha=5$ percent. Since the estimated values of $\tau$ were smaller than the statistic of the test, the conclusion is that, both series are non-stationary.

The same applies to the model of Equation (2). The values of $\tau$ were -2.0197 and -1.6134 for PLATTS and LME respectively. Obviously, these are lower than the statistic obtained whose value were -2.9176 for $\alpha=5$ percent. For Equation (3), the values of $\tau$ were -1.9816 and -1.5674 for PLATTS and LME respectively. The corresponding value of the test statistic were -3.4969 for the same value of $\alpha$.

Therefore, based on the graphical analysis, the correlograms, the LjungBox test and the Dickey-Fuller test, the conclusion is that the prices of the aluminum published monthly during the period from January 2009 to July 2013 in PLATTS and LME are non-stationary time series.

\section{Conclusions}

The tests carried out in the prices of the aluminum published by LME and PLATTS demonstrate that changes of these in the international market are 
non-stationary. Also, it was proved that these indices are asymmetric negative indicating that in both cases there is a greater likelihood that there are big falls and increases in price values. The Jarque-Bera Statistical Test of distributions of the indices showed that these are distributed normally. Therefore, the economic hypothesis with we start this research $\left(H_{0}\right.$ : The international aluminum market is efficient). In this sense it can be said with sufficient statistical evidence that international aluminum market represented by the PLATTS and LME indices are efficient from the economic point of view, for the period from January 2009 to July 2013.

\section{References}

[1] E. Fama. Random walks in stock markets. Financ. Anual J., Vol. 4, (1965), pp. 55-59.

[2] R. Brealy and S. Maters. Principles of Corporate Finance. Mc Graw Hill, Madrid, 5ta, (1995).

[3] S. Ross, R. Westerfield and J. Jaffe, Corporate Finances. Irwin Mexico, 3ra, (1995), pp 1-9.

[4] Luis Mariano Rodríguez and José Simón Fermín. Efficient market and random walk on the Caracas stock exchange, Interciencia, Vol. 31(12), (2005), pp 888-893.

[5] D. Guajarati. Econometrics, Mc Graw Hill, Mexico, (2003).

[6] M.G Kendall. The analysis of economic time series, part I: Prices, J. Royal Stat. Soc., Vol. 96, (1953).

[7] H. Roberts. Stock market patterns and financial: Analysis, J. Finance, Vol. 14, (1959), pp 1-10.

[8] M.F. Osborne. Brownian motion in the stock market, Operations Res, Vol. 7, (1957), pp 145-173.

[9] E. Risuol. Evidence of linearity in financial series, Gaceta Econ., Vol. 17, (2003), pp 208-233.

[10] L. Bachelier. Theorie de a Speculation, Cambridge MA, Vol. 81, (1964), pp 70 . 
[11] K.V. Chow and K. Denning. A simple multiple variance ratio test, Journal Econ., Vol. 58, (1993), pp 385-401.

[12] G. Box and M. Pierce. Distribution of residual autocorrelation in autoregresive integrated moving average time series models, J. Royal Stat. Soc., Vol. 65, (1970), pp 1509-1526.

[13] S. Dezelan. Efficiency of the slovenian equity market, Economic and Business Review, Vol. (12), (2000), pp 61-83.

[14] M. Reglez and A. Zarraga. Common features between stock returns and trading volume, Applied Financial Economics, Vol.(12), (2002), pp 885893.

[15] J. Hajek. Weak-Form efficiency in the Czech equity market, Queueing Systems, Vol. 50 (3), (2002), pp 377-389.

[16] S.H Poon. Persistence and mean reversion in UK stock returns, European Financial Management, Vol.2 (2), (1996), pp 169-196.

[17] A.C. Worthington and H. Higgs. Random walks and market efficiency in european equity markets, Global Journal of Finance and Economics, Vol.1 (1), (2004), pp 59-78.

[18] María Rosa Borges. Efficient market hypothesis in european stock markets, Journal Technical University of Lisbon, Vol.3 (2), (2008), pp 53-68.

[19] A. Moore. A Statistical Analysis of Common Stock Prices, University of Chicago, (1962).

[20] Peter S. Sephton and Donald K. Cochrane. The efficiency of the london metal exchange: another look at the evidence, Applied Financial Economics, Vol. 23, (1991), pp 669-674.

[21] Dimitris Kenourgios and Aristeidis G. Samitas. Testing efficiency of the copper futures market: New evidence from London Metal Exchange, BEESI Conference in Rhodes Greece, (2004).

[22] Gwanak-Ro and Gwanak-gu. Testing of market efficiency in international metal market, Geosystem Engineering, Vol.13 (2), (2010), pp 53-55.

[23] J.Y. Campbell, A.W Lo, and A.C. Mackinlay. The Econometrics of Financial Markets, Princeton University Press, Princeton NJ, EEUU, (1997), pp 632. 
[24] G.M Ljung and G.P.E Box. On a measure of lack of time series models, Biometrika, (1978), pp 66-72.

[25] D.A Dickey and W.A Fuller. Distribution of the estimators for autoregressive time series with a unit root, J. Am. Stat. Assoc., 74, (1979), pp 427-431.

[26] J.G. MacKinnon. Critical values de cointegration test, En Engle $R$, Granger GWJ (Eds.), Long run Economic Relation-ships: Readings in Cointegration. Oxford University Press. Nueva York, NY, EEUU., (1991), pp 267-276.

[27] Phillips P.C.B. and Perron P. Testing for a Unit Root in Time Series Regression, Biometrika, (75), (1991), pp 335-346.

[28] Barlett M.S. On the theoretical specification of sampling properties of autorrelated time series, Journal of the Royal Statistical Society, Series B, Vol. (27), (1946).

[29] Lo. A.W and A.C. MacKinlay. Stock market prices do not follow random walks: Evidence from a simple specification test, The Review of Financial Study, (1),(1988), pp 41-66.

[30] Kwiatkowski, D., P. Phillips, P. Schmidt and Y. Shin. Testing the null of stationarity against the alternative of a unit root, Journal of Econometrics, Vol. 54, (1992), pp 159-178.

[31] S. Sidney. Statistics Non-Parametric, 3ra Ed., Mexico, Trillas, (1990).

[32] Malkiel, Burton G., 2005. Reflections on the efficient market hypothesis: 30 years Later, The Financial Review, 40 (1), 1-9. 